\title{
Re-Layout Penempatan Fasilitas Produksi dengan menggunakan Metode Systematic Layout Planning dan Metode 5 S Guna Meminimalkan Biaya Material Handling
}

\author{
Esa Rengganis ${ }^{1}$, Uyuunul Mauidzoh ${ }^{2}$ \\ 1,2) Jurusan Teknik Industri, Sekolah Tinggi Teknologi Adisutjipto \\ Jl. Janti Blok R Lanud Adisutjipto, Karang Jambe Banguntapan Bantul \\ Email : esarengganisstta@gmail.com,yun_mdz@yahoo.com
}

\begin{abstract}
ABSTRAK
Perencanaan fasilitas memiliki pengaruh yang sangat besar pada sebuah proses produksi. Penelitian akan dimulai dari lantai produksi untuk mengamati tata letak departemen, pergerakan yang terjadi selama proses produksi sampai dengan penyimpanan produk setengah jadi dan produk jadi. CV. Jakudo Kamsa merupakan salah satu industri yang bergerak pada proses pengolahan kulit, dari bahan mentah sampai dengan produk produk mereka. Berdasarkan pengamatan yang dilakukan di lantai produksi, CV. Jakudo Kamsa, didapatkan permasalahan setengah jadi yang menjadi input bagi perusahaan sepatu maupun tas yang menggunakan kulit sebagai bahan baku utama bagi produk bahwa peletakan peralatan produksi belum optimal sehingga aliran material yang ada kurang baik. Hal ini dapat menyebabkan ongkos material handling yang cukup besar dan terjadi kesimpangsiuran pekerja maupun bahan baku pada saat proses produksi.Dengan kondisi seperti ini, maka sering terjadi delay pada proses produksi dan otomatis hal ini mengakibatkan tenaga kerja yang menganggur.Sehingga perlu dilakukan re-layout pada pengaturan peralatan produksi agar proses produksi lebih optimal.

Metode yang digunakan untuk memperbaiki layout departemen produksi adalah Metode Systematic Layout Planning dan metode $5 \mathrm{~S}$. Kedua metode ini dikombinasikan untuk mengoptimalkan layout departemen produksi sehingga meminimalkan biaya material handling. SLP merupakan metode yang digunakan untuk mengatur lantai produksi berdasarkan tingkat frekuensi pergerakan dan hubungan kedekatan. Sedangkan metode $5 \mathrm{~S}$ merupakan alat yang paling efektif dan sederhana untuk mengatur area kerja. Tujuan dari metode $5 \mathrm{~S}$ adalah menciptakan lingkungan kerja yang bersih sehingga diharapkan produktivitas atau kinerja akan meningkat.

Berdasarkan pengumpulan dan pengolahan data yang dilakukan pada tahap sebelumnya didapatkan hasil biaya OMH sebelum dilakukan relayout sebesar Rp. 346.190,5. Berdasarkan hasil relayout didapatkan penurunan biaya material handling. Biaya material handling yang semula Rp. 346.190,5 menjadi Rp. 327.226,1. Setelah proses relayout dilakukan maka dilakukan analisa dan evaluasi dengan menggunakan metode $5 \mathrm{~S}$. Berdasarkan hasil penelitian pada saat ini didapatkan hasil bahwa layout departemen produksi yang ada sekarang ini belum optimal. Hal ini ditunjukkan dengan tingginya ongkos material handling, yaitu sebesar Rp. 346.190,5. Kemudian dilakukan pertukaran antara departemen Pencucian, Penyamakan, dan Penghalusan. Pertukaran ketiga departemen ini akan menurunkan ongkos material handling sebesar Rp. 18.924,4, sehingga ongkos material handling menjadi Rp. 327.266,1.Berdasarkan hasil evaluasi dengan menggunakan metode $5 \mathrm{~S}$ perlu dilakukan penambahan rak peletakan perlengkapan kerja dan tools dan rak untuk meletakkan produk setengah jadi.
\end{abstract}

Kata Kunci : Relayout, systemic layout planning, metode 5S, biaya material handling

\section{ABSTRACT}

Facility planning have a great influence on production process. Research will be started from production division, departement layout, raw material, workers and tools's movement on production process will be observe. Relayout will be done based on calculation these movement. CV. Jakudo Kamsa is an industry that is enganged in the processing of leather, from raw materials to their products. Based on observation made on the production floor, CV. Jakudo Kamsa, there is a semi-finished problem which is an input for shoe and bag companies that use leather as the main raw material for product that the production equipment laying is not optimal so that flow of existing materials is not good. This can cause considerable maaterial handling cost and confusion between workers and raw materials during the production process. With these conditions there is often a delay in the 
production process and automatically this results in unemployed workers. So it is necessary to re-layout on setting production equipment so that the production process is more optimal.

Relayout method that will use on this research are Systematic Layout Planning and 5 S. Both of methods will be combine to optimize production layout until we find the smallest material handling cost. Systematic layout plannuing ia a tool used to arrange a workplant in a plant by locating area with high frequency and logical relationships close to each other. The process permits the quickest material flow in processing the product at the lowest cost and least amount of handling. $5 \mathrm{~S}$ is a highly effective and simple tool to ensure the workplace is effieciently organized. The primary objective of $5 \mathrm{~S}$ is to create a clean, orderly enviroment. The $5 \mathrm{~S}$ is a set of straight forward steps towards continual improvemnet.

Based on data research we found initial layout material handling cost on Rp. 346190.5. and material handling cost relayout is Rp. 327226, 1. Material handling cost decrease amoung Rp. 18964,4. Based on 5 S eavaluation we needs rack addition to put work equipment, tools and product in process.

Keywords : Relayout, systematic layout planning, 5S method, material handling cost

\section{PENDAHULUAN}

Perkembangan teknologi yang sangat pesat berdampak besar pada setiap aktivitas kegiatan industri. Salah satu dampak yang paling terasa adalah pengaturan fasilitas produksi. Munculnya peralatan produksi ataupun metode produksi baru berpengaruh pada pengaturan fasilitas produksi. CV. Jakudo Kamsa merupakan salah satu industri yang bergerak pada proses pengolahan kulit, dari bahan mentah sampai dengan produk setengah jadi yang menjadi input bagi perusahaan sepatu maupun tas yang menggunakan kulit sebagai bahan baku utama bagi produk-produk mereka. Berdasarkan pengamatan yang dilakukan di lantai produksi, CV. Jakudo Kamsa, didapatkan permasalahan bahwa peletakan peralatan produksi belum optimal sehingga aliran material yang ada kurang baik. Hal ini dapat menyebabkan ongkos material handling yang cukup besar dan terjadi kesimpangsiuran pekerja maupun bahan baku pada saat proses produksi.Dengan kondisi seperti ini, maka sering terjadi delay pada proses produksi dan otomatis hal ini mengakibatkan tenaga kerja yang menganggur.Sehingga perlu dilakukan $r e-$ layout pada pengaturan peralatan produksi agar proses produksi lebih optimal.

Adapun permasalahan yang ada di lantai produksi CV Jakudo Kamsa adalah adanya penempatan fasilitas yang kurang tepat. Hal ini menyebabkan tingginya ongkos material handling. Dalam penelitian ini, masalah yang akan dipecahkan adalah bagaimana penempatan tata letak fasilitas yang optimal sehingga dapat meminimasi ongkos material handling dan persimpangan perpindahan material dan pekerja dengan menggunakan metode Systemic Layout Planning dan $5 \mathrm{~S}$

Dalam penelitian imi erdapat beberapa hal yang menjadi batasan penelitian yang akan dilakukan di CV. Jakudo Kamsa. Adapun yang jadi batasan dalam penelitian ini adalah; 1) Penelitian dilakukan di lantai produksi CV. Jakudo Kamsa, 2) Re-layout akan dilakukan dengan menggunakan metode Systemic Layout Planning dan 5 S.

Tujuan dari penelitian ini adalah melakukan penataan ulang tata letak fasilitas atau re-layout lantai produksi di CV. Jakudo Kamsa sehingga dapat meminimasi ongkos material handling dan kesimpang siuran material maupun pekerja dan meminimalkan kecacatan produk.

\section{METODE PENELITIAN}

Untuk menyelesaikan permasalahan yang dihadapi CV. Jokudo digunakan metode Systemic Layout Planning dan metode $5 \mathrm{~S}$. Metode SLP dipilih karena metode ini mencoba merancang layout fasilitas dengan memperhatikan urutan proses serta derajat kedekatan antar departemen yang terdapat pada lantai produksi yang akan dirancang. Sedangkan metode S digunakan karena diharapkan semua aktivitas yang akan diterapkan dapat diikuti oleh semua individu yang terlibat pada departemen produksi.

\subsection{Metode Systemic Layout Planning}

Tahapan yang di gunakan untuk perancangan tata letak fasilitas pabrik sesuai dengan pendekatan Systematic Layout Planning (SLP) menurut Purnomo (2004) terdiri dari tiga tahapan. Tahapan pertama adalah tahap analisis, mulai dari analisis aliran material, analisis aktivitas, diagram hubungan aktivitas, pertimbangan keperluan ruangan dan ruangan yang tersedia. Tahapan kedua adalah tahap penelitian, mulai dari perencanaan diagram hubungan ruangan sampai dengan perancangan alternatif tata letak. Sedangkan tahapan ketiga adalah proses seleksi dengan jalan mengevaluasi alternatif tata letak yang telah dirancang. Data-data yang diperlukan untuk 
perencanaan tata letak dengan menggunakan metode SLP yaitu data rancangan produk, rancangan proses dan rancangan jadwal produksi.

1. Penentuan Kapasitas Produksi

Dalam pememenuhan order produksi yang diterima perusahan harus diketahui apakah dapat di penuhi sesuai dengan kemampuan kapasitas produksi yang terpasang pada perusahaan. bila ada kelebihan order produksi dapat dilakukan dengan cara lembur atau sub kontrak dengan dilimpah kan ke perusahan lain. Dalam menentukan kapasitas produksi menggunakan data produk yang sering di pesan dan diproduksi dalam jumlah yang besar (produk acuan) dalam 3 bulan penelitian.

2. Penentuan Jarak Antar Fasilitas Produksi Pada Layout Awal

Jarak antar stasiun kerja dapat diketahui dengan melakukan menentukan pusat antara stasiun kerja Selanjutnya adalah perhitungan jarak dengan menggunakan sistem jarak siku (rectilinear), yaitu jarak yang diukur antara pusat stasiun kerja satu dengan pusat stasiun kerja lainnya. Masing - masing stasiun kerja dicari titik pusatnya yaitu 0 dari $\mathrm{X}$ dan $\mathrm{Y}$. Alasan menggunakan metode ini adalah lintasan/jalur pengangkutan aliran yang dilalui oleh material maupun produk setengah jadi.

Rumus yang digunakan adlalah sebagal berikut :

$$
\mathrm{d} i j=x_{i}-x_{j}+y_{i}-y_{j}
$$

di mana: $X i=$ koordinat $x$ pada pusat fasilitas $i$

$$
\begin{aligned}
Y i & =\text { koordinat } y \text { pada pusat fasilitas } i \\
d i j & =\text { jarak atara pusat fasilitas } i \text { dan } j
\end{aligned}
$$

3. Penentuan Performansi Layout Awal dan Ongkos Material Handling Layout Awal

Dari perhitungan jarak antar stasiun kerja di atas, dapat diketahui performansi layout awal yaitu Total jarak material handling (D)

$$
\mathrm{D}=\sum_{j=1}^{n} d j . .
$$

dimana : $\quad \mathrm{D}=$ Total jarak material handling

$d j=$ jarak material handling untuk tiap - tiap stasiun kerja

$n$ = Banyaknya stasiun kerja

4. Penentuan Alternatif Tata Letak Usulan Terpilih atau Diterima.

Dalam penetuan alternatif terpilih ini diperoleh dari hasil perhitungan jarak yang paling minimal.

$D j k=D j a-D j u$

Min DJK $=\sum D j k$

Dimana : Djk = selisih jarak untuk masing - masing stasiun kerja

Dja = jarak material handling tata letak awal

Dju $=$ jarak material handling tata letak usulan

DJK $=$ jarak material handling yang terpilih terpilih.

\subsection{Ongkos Material Handling}

Di dalam merancang tata letak pabrik, maka aktivitas pemindahan bahan merupakan salah satu hal yang cukup penting untuk diperhatikan dan diperhitungkan. Tujuan dari pemindahan bahan adalah sebagai berikut:

1. Menaikkan kapasitas.

2. Memperbaiki kondisi kerja.

3. Memperbaiki pelayanan pada pelanggan.

4. Meningkatkan pemanfaatan ruang dan peralatan.

5. Mengurangi ongkos.

Beberapa aktivitas material handling yang perlu diperhitungkan adalah pemindahan bahan menuju gudang bahan baku dan keluar dari gudang jadi serta pemindahan atau pengangkutan yang terjadi di dalam pabrik saja. Faktor - faktor yang mempengaruhi perhitungan ongkos material handling diantaranya adalah jarak tempuh dari satu stasiun kerja ke stasiun kerja yang lain dan ongkos pengangkutan per meter gerakan. Pengukuran jarak tempuh tersebut disesuaikan dengan kondisi yang ada di lapangan. Dengan demikian, jika jarak tempuh sudah ditentukan dan frekuensi material handling sudah diperhitungkan maka ongkos material handling dapat diketahui, dimana :

Total OMH $=($ Ongkos per meter gerakan $) \times($ Jarak tempuh pengangkutan $) \times($ Frekuensi $)$. 
Perhitungan Ongkos material handling per meter gerakan terdiri dari 2 macam yaitu :

a. Material handling dengan tenaga manusia

$\mathrm{OMH} / \mathrm{m}=\frac{\text { omh } / \text { bulan }}{\text { total jarak }}$

b. Material handlingdengan alat, menggunakan perhitungan :

Biaya Alat $=\frac{\text { biaya pembelian-nilai sisa }}{\text { umur ekonomis }}$

sehingga didapatkan :

Total OMH $=(\mathrm{OMH}$ per meter $) \times$ jarak tempuh $x$ frekuensi

\subsection{Metode $5 \mathrm{~S}$}

Perbaikan kondisi lingkungan kerja pada pabrik ini dapat dilakukan dengan menerapkan metode 5S. 5S adalah prinsip yang paling mudah dipahami, prinsip ini memungkinkan untuk memperoleh partisipasi secara total. Merujuk kepada pendapat seorang pakar bahwa tidak akan berhasil bila 5S tidak diterapkan, sebaliknya keuntungan yang diperoleh bila dengan menerapkan $5 \mathrm{~S}$ akan terlihat dengan jelas, diantaranya terciptanya keteraturan melalui manajemen lingkungan kerja yang baik. Menurut Linstiani (2010) penjabaran dari metode " $5 \mathrm{~S}$ " adalah sebagaimana berikut:

1. Seiri (Sisih/Ringkas) . Menyisihkan barang-barang yang tidak diperlukan ditempat kerja. Prinsip dalam menerapkan konsep yang pertama ini adalah mengidentifikasi dan menjauhkan barang yang tidak diperlukan di tempat kerja.

2. Seiton (Penataan). Menata barang-barang yang diperlukan supaya mudahditemukan oleh siapa saja bila diperlukan. Setiap barang mempun yai tempat yang pasti, jelas dan diletakkan pada tempatnya. Adapun metode yang dapat digunakan adalah pengelompokan barang, penyiapan tempat, memberi tanda batas, memberi tanda pengenal barang, membuat denah/peta pelaksanaan barang

3. Seiso (Pembersihan). Membersihkan tempat kerja dengan teratur sehingga tidakterdapat debu di lantai, mesin dan peralatan. Prinsip: bersihkan segala sesuatu yang ada di tempat kerja. Membersihkan berarti memeriksa dan menjaga.

4. Seiketsu (Pemantapan). Memelihara taraf kepengurusan rumah tangga yang baikdan organisasi tempat kerja setiap saat. Prinsip: semua orang memperoleh informasi yang dibutuhkan dengan tepat waktu. Pertahankan lingkungan 3S (Sisih, Susun, Sasap) yang telah dicapai, cegah kemungkinan terulang kotor/rusak.

5. Shitsuke (Pembiasaan). Memberikan penyuluhan kepada semua orang agarmematuhi disiplin pengurusan rumah tangga yang baik atas kesadaran sendiri. Prinsip: berikan pengarahan kepada orang-orang untuk berdisiplin mengikuti cara dan aturan penanganan house keeping atas dasar kesadaran. Lakukan apa yg harus dilakukan dan jangan melakukan apa yang tidak boleh dilakukan.

Sedangkan tahapan pengolahan data untuk penerapan $5 \mathrm{~S}$ yang diperolah adalah sebagai berikut:

1. Perancangan Metode 5S

Tahap ini merupakan tahap paling awal dari penerapan metode 5S, pada tahap ini dilakukan perancangan metode 5S. Maksud perancangan disini adalah lebih kepada perencanaan apa saja yang akan dilakukan nantinya pada tahap penerapan. Misalnya saja menentukan lokasi yang dianggap bermasalah, menentukan peralatan apa saja yang perlu diterapkan metode $5 \mathrm{~S}$ ini serta bagaimana cara untuk menaggulanginya.

2. Sosialisasi Metode 5S

Tahap sosialisasi ini adalah tahapan selanjutnya setelah perancangan dilakukan. Pada tahap ini melalui bantuan dari pimpinan perusahaan dilakukan sosialisasi kepada semua karyawan mengenai penerapan metode 5S yang akan dilakukan. semua karyawan diberikan penjelasan tentang pengertian, tujuan serta manfaat dari metode 5S. Selain itu juga diberikan sosialisasi tentang rancangan metode $5 \mathrm{~S}$ yang telah dibuat.

3. Penerapan Metode 5S

Tahapan ini merupakan proses penerapan yang akan dilakukan setelah dilakukan proses perancangan dan sosialisasi 5S. Tahapan ini dilakukan untuk merelisiasikan perancangan metode $5 \mathrm{~S}$ yang telah dibuat ada 5 aspek yang akan diterapkan yaitu seiri, seiton, seiso, seiketsu, dan shitsuke.

4. Evaluasi Penerapan Metode 5S

Pada tahap ini dilakukan proses evaluasi terhadap penerapan yang telah dilakukan. Dari evaluasi ini nantinya bisa diketahui apa saja yang telah diterapkan dan apa saja yang menjadi kendala pada penerapan 
metode ini dan pada tahap evaluasi ini juga dilakukan proses pengecekan kegiatan yang dilakukan dengan menggunakan tabel evaluasi kegiatan

Setelah selesai tahapan-tahapan di atas maka langkah selanjutnya yang dilakukan adalah membuat layout akhir berdasarkan kombinasi antara alternatif tata letak terbaik dan perancangan metode $5 \mathrm{~S}$.

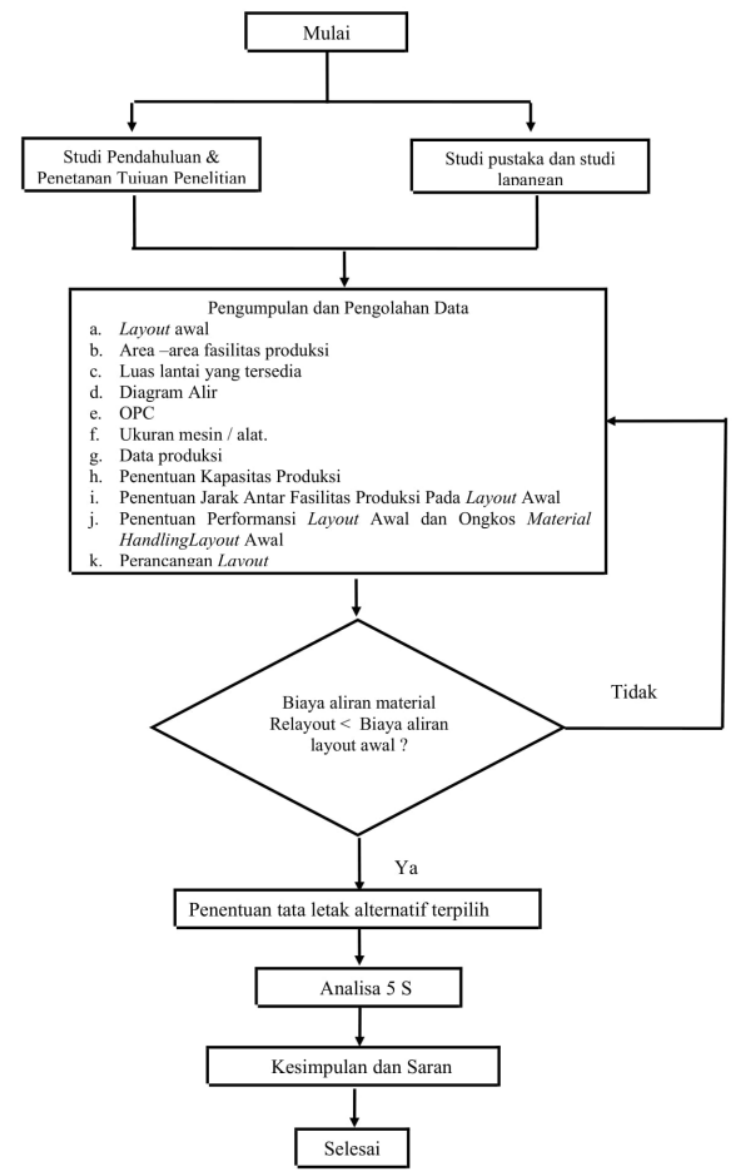

Gambar 1. Diagram Alir Penelitian

\section{HASIL DAN PEMBAHASAN}

\subsection{Pengumpulan dan Pengolahan Data Departemen Produksi}

1. Data Luasan Departemen

Bagian produksi Cv. Jakudo terdiri dari 7 departemen. Luas tiap departemen dapat dilihat pada Tabel 1 .

Tabel 1. Luas Departemen Pada Lantai Produksi

\begin{tabular}{clcc}
\hline No & \multicolumn{1}{c}{ Departemen } & Ukuran $(\mathrm{P} \times \mathrm{L})(\mathrm{m})$ & Luas $\left(\mathrm{m}^{2}\right)$ \\
\hline A & Pencucian & $4,05 \times 3,45$ & 13,97 \\
B & Penyamakan & $4,05 \times 5,90$ & 15,79 \\
C & Penghalusan & $4,90 \times 2,90$ & 14,21 \\
D & Penjemuran & $6,00 \times 4,90$ & 29,40 \\
E & Penimbangan & $1,50 \times 1,25$ & 1,875 \\
F & GudangBahan Kimia & $4,00 \times 3,00$ & 12,00 \\
G & Penyimpanan Air & $2,00 \times 1,75$ & 3,50 \\
\hline
\end{tabular}


Sedangkan untuk Block Layout dapat dilihat pada gambar 2. Block Layout menggambarkan setiap departemen dengan ukuran dan letaknya seperti pada lantai produksi di pabrik.

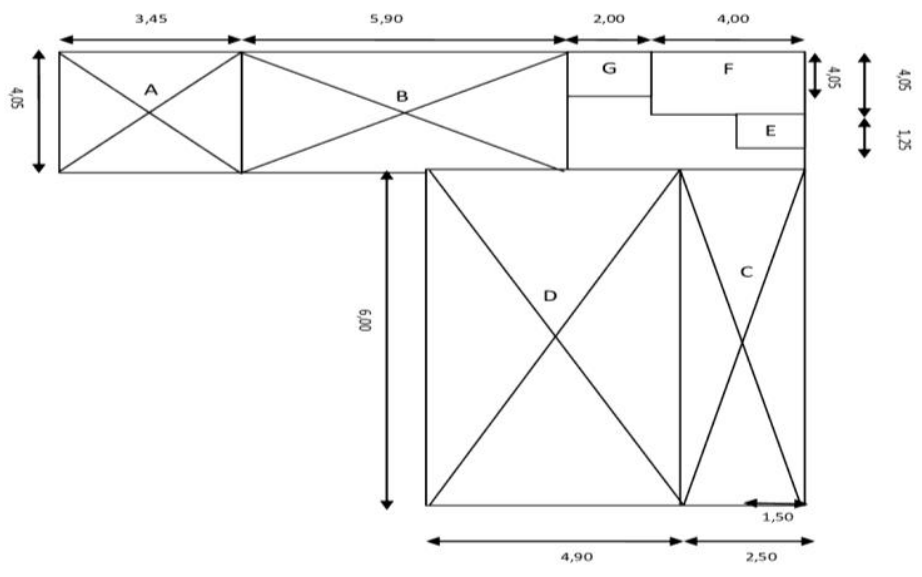

Gambar 2. Layout Awal Lantai Produksi

2. Mesin-mesin Produksi yang digunakan dan ukurannya

Mesin - mesin dan peralatan yang digunakan dalam proses produksi dapat dilihat pada tabel 2.

Tabel 2. Tabel Mesin dan Peralatan Produksi

\begin{tabular}{lcccc}
\hline \multicolumn{1}{c}{ Nama } & \multicolumn{4}{c}{ KarakteristikMesin } \\
Mesin & Jumlah & Panjang & Lebar & Diameter \\
\hline Rotary Drum & 3 & 3,55 & 2,45 & 1,8 \\
Buffing & 5 & 0,63 & 0,58 & - \\
Genset Kecil & 1 & 0.70 & 0.55 & - \\
Timbangan & 1 & 0.80 & 0.50 & - \\
PalangKayu & 6 & 5,50 & 0.15 & - \\
\hline
\end{tabular}

3. Jumlah Produksi

Berdasarkan hasil pengamatan selama 3 bulan jumlah kulit yang disamak atau diproduksi rata-rata sebanyak 4200 sqft per bulan. Sehingga dalam jangka waktu 3 bulan jumlah kulit yang disamak kurang lebih $12600 \mathrm{sq} \mathrm{ft}$.

4. Penentuan Frekuensi Perpindahan dan Jarak Perpindahan Stasiun Kerja

Penentuan fekuensi perpindahan antar stasiun kerja adalah berapa jumlah satuan / unit yang dapat dipindahkan dalam sekali perpindahan serta perpindahan tersebut berapa kali dilakukan dalam satuan waktu (bulan). Data perpindahan bahan dapat dilihat seperti pada tabel 3.

Tabel 3. Tabel Frekuensi Material Handling

\begin{tabular}{ccccc}
\hline From & To & AlatAngkut & Kapasitas MH (Unit) & Total MH \\
\hline A & B & Arco Sorong & $50 \mathrm{~kg}$ & 10 \\
B & D & Arco Sorong & $50 \mathrm{~kg}$ & 10 \\
B & E & Arco Sorong & $50 \mathrm{~kg}$ & 10 \\
C & D & Selang & $100 \mathrm{liter}$ & 15 \\
C & E & Selang & $100 \mathrm{liter}$ & 15 \\
D & E & Arco Sorong & $50 \mathrm{~kg}$ & 5 \\
\hline
\end{tabular}


Tabel 3. Tabel Frekuensi Material Handling (lanjutan)

\begin{tabular}{ccccc}
\hline From & To & AlatAngkut & Kapasitas MH (Unit) & Total MH \\
\hline E & $\mathrm{F}$ & Arco Sorong & $50 \mathrm{~kg}$ & 5 \\
$\mathrm{~F}$ & $\mathrm{G}$ & Arco Sorong & $50 \mathrm{~kg}$ & 10 \\
$\mathrm{~F}$ & $\mathrm{H}$ & Arco Sorong & $50 \mathrm{~kg}$ & 10 \\
\hline
\end{tabular}

5. Biaya Material Handling Manual

Ongkos material handling untuk setiap kali pengangkutan ditentukan berdasarkan ongkos per meter gerakan, dimana didalam ongkos tersebut sudah dipertimbangkan biaya pembelian dan depresiasi alat, serta biaya tenaga kerja.

a. Biaya pembelian dan depresiasi alat

Peralatan yang digunakan untuk memindahkan material utama dan material pembantu produk yang sedang diolah adalah gerobak sorong Arco dan selang air dengan diameter $4 \mathrm{~cm}$.

Harga beli gerobak Arco sebesar Rp. 650.000 dan mempunyai umur ekonomis selama 10 tahun. Jumlah gerobak Arco adalah 3 buah.

Maka biaya OMH untuk gerobak Arco $=(\Sigma$ Alat Angkut x Harga / unit $) /(24$ hari x $12 \times 10)$.

Biaya $\mathrm{OMH}=\frac{3 \times 650000}{24 \times 12 \times 10}=\mathrm{Rp} .677,08$, frekuensi pemakaian sebulan rata-rata 65 kali.

Biaya OMH untuk sekali pakai $=$ Rp. 677,08 / $65=$ Rp. 10,41

Sedangkan untuk selang air yang dipakai memiliki umur ekonomis selama 8 tahun. Harga beli sebesar Rp. 28.000 / meter. Panjang selang 10 meter dan frekuensi pemakaian selama 1 bulan adalah 20 kali.

Maka OMH untuk selang air $=($ Rp. 28.000 x 10$) /(24 \times 12$ x 8) $=$ Rp. 121,52.

Biaya OMH untuk sekali pakai $=$ Rp. 121,52 / $20=$ Rp. 6,076

b. Biaya tenaga kerja

Biaya perpindahan yang dikerjakan oleh tenaga manusia didasarkan pada perhitungan waktu perpindahan yang dilakukan.

Gaji yang diterima oleh setiap pekerja adalah Rp. 950.000. Jumlah pekerja sebanyak 4 orang. Maka gaji per bulan tersebut harus dikonversikan ke dalam satuan menit. 1 bulan kerja terdapat 24 hari kerja.

Gaji pekerja per menit untuk 4 orang pekerja $=\frac{950000 \times 4}{24 \times 420}=R p .376,98 /$ menit

Untuk seorang pekerja per menit $=\frac{376,98}{4}=$ Rp. 94, $24 /$ menit

Tabel 4. Tabel Ongkos Perpindahan Tenaga Kerja

\begin{tabular}{clccccc}
\hline No & Stasiun & $\begin{array}{c}\text { Waktu } \\
\text { Perpindahan } \\
\text { (menit) }\end{array}$ & $\begin{array}{c}\text { Gaji } \\
\text { (menit) }\end{array}$ & $\begin{array}{c}\text { Ongkos } \\
\text { Perpindahan } \\
\text { (menit) }\end{array}$ & Frekuensi & $\begin{array}{c}\text { Ongkos } \\
\text { Perpindahan } \\
\text { (bulan) }\end{array}$ \\
\hline 1 & Penimbangan & 10 & 94.24 & 942.4 & 10 & 9424 \\
2 & Tangki Air & 15 & 94.24 & 1413.6 & 10 & 14136 \\
3 & Rotary Drum & 40 & 94.24 & 3769.6 & 10 & 37696 \\
4 & Tanning & 40 & 94.24 & 3769.6 & 10 & 37696 \\
5 & Penjemuran & 50 & 94.24 & 4712 & 5 & 23560 \\
6 & Splitting & 40 & 94.24 & 3769.6 & 10 & 37696 \\
7 & Penggudangan & 30 & 94.24 & 2827.2 & 10 & 28272 \\
\hline
\end{tabular}


Secara ringkas ongkos material handling untuk layout awal dapat dilihat pada tabel 5.

Tabel 5. Tabel Ongkos Material Handling Layout

\begin{tabular}{lccccc}
\hline From & To & $\begin{array}{c}\text { OMH } \\
\text { TK }\end{array}$ & $\begin{array}{r}\text { OMH } \\
\text { Alat }\end{array}$ & $\begin{array}{r}\text { Dij } \\
\text { x } \\
\text { F }\end{array}$ & $\begin{array}{c}\text { OMH / } \\
\text { Meter }\end{array}$ \\
\hline A & B & 9424 & 16250 & 28,5 & 900,84 \\
B & D & 14136 & 16250 & 130,25 & 233,29 \\
B & E & 37696 & 16250 & 84 & 642,21 \\
C & D & 37696 & 121,52 & 105,375 & 358,88 \\
C & E & 23560 & 121,52 & 85,5 & 276,97 \\
D & E & 37696 & 16250 & 23,625 & 2283,43 \\
E & F & 28272 & 16250 & 55 & 809,50 \\
F & G & 9424 & 16250 & 35,5 & 723,21 \\
F & H & 14136 & 16250 & 107 & 283,98 \\
\hline
\end{tabular}

Tabel 6. Tabel kebutuhan luas area keseluruhan

\begin{tabular}{lccc}
\hline \multicolumn{1}{c}{ Departemen } & LembarKebutuhanLuas Area SecaraKeseluruhan & \\
& Luas $^{2} \mathrm{~m}^{2}$ & JumlahFasilitas & Total Luas $\left(\mathrm{m}^{2}\right)$ \\
\hline Pencucian & 13,97 & 1 & 13,97 \\
Penyamakan & 15,79 & 1 & 15,79 \\
Penghalusan & 14,21 & 1 & 1,21 \\
Penjemuran & 29,40 & 1 & 29,40 \\
Penimbangan & 1,875 & 1 & 1,875 \\
GudangBahan Kimia & 12 & 1 & 12 \\
Penyimpanan Air & 3,5 & 1 & 3,5 \\
RuangIstirahat & 15 & 1 & 15 \\
Toilet & 12 & 1 & 12 \\
Parkir & 24 & 1 & 24 \\
& Total Luas Area & & 128,745 \\
\hline
\end{tabular}

Untuk me re-layout departemen yang ada digunakan algoritma CRAFT dengan bantuan Quant System. Terdapat beberapa perubahan layout yang dapat dilakukan beberapa perubahan yang dapat dilakukan adalah dengan cara menukar letak 2 buah departemen, merubah letak 3 buah departemen, merubah letak 2 departemen kemudian dilanjutkan dengan merubah letak 3 departemen, perubahan letak 3 departemen kemudian dilanjutkan dengan perubahan letak 2 departemen.

Besarnya ongkos material handling untuk perubahan yang terjadi dapat dilihat pada tabel berikut.

Tabel 7. Tabel Pertukaran Departemen

\begin{tabular}{clc}
\hline No & \multicolumn{1}{c}{ Layout } & Total Ongkos Material Handling \\
\hline 1 & Awal & Rp. 346.190,5 \\
2 & Pertukaran 2 Departemen & \\
& a. Pertukaran A dan B & Rp. 330.176,1 \\
& b. Pertukaran B dan C & Rp. 327..226,1 \\
3 & Pertukaran 3 Departemen A, B, C & Rp. 327.226,1 \\
4 & Pertukaran 2 departemendilanjutkanpertukaran 3 departemen & Rp. 327.226,1 \\
5 & Pertukaran 3 departemendilanjutkanpertukaran 2 departemen & Rp. 327.226,1 \\
\hline
\end{tabular}


Sedangkan layout hasil relayout dapat dilihat pada gambar 3.

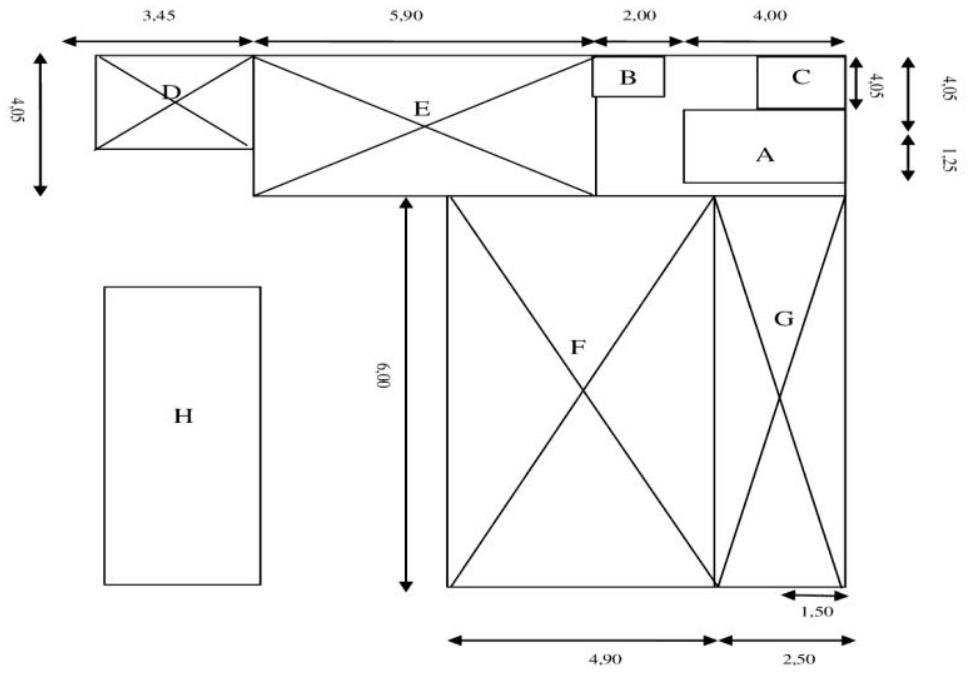

Gambar 3. Relayout Lantai Produksi

\subsection{Pembahasan}

Berdasarkan pengumpulan dan pengolahan data yang dilakukan pada tahap sebelumnya didapatkan hasil biaya OMH sebelum dilakukan relayout sebesar Rp. 346.190,5. Kemudian berdaasarkan analisa diagram alir dan aktivitas yang dilakukan oleh tenaga kerja maka diambil keputusan untuk melakukan Pertukaran 3 departemen dilanjutkan pertukaran 2 departemen. Pertukaran atau relayout ini dilakukan dengan menggunakan bantuan CRAFT. Berdasarkan hasil relayout didapatkan penurunan biaya material handling. Biaya material handling yang semula Rp. 346.190,5 menjadi Rp. 327.226,1.

Setelah proses relayout dilakukan maka dilakukan evaluasi dengan metode $5 \mathrm{~S}$, yaitu Seiri, Seiton, Seiso, Seiketsu dan Shitsuke.

1. Seiri.

Konsep ini berhubungan dengan pemilahan barang atau produk yang sangat bermanfaat untuk proses suatu pabrik atau perusahaan. Pastikan tiap barang yang berbeda jenis maupun keperluan dipisahkan. Dengan memisahkan barang atau produk yang sama dalam satu box yang sama dimaksudkan agar tidak sampai ke tangan pelanggan. Pencampuran barang yang sama kadang bisa sampai ke tangan pelanggan. Metode ini banyak diterapkan pada departemen bahan baku. Pada departemen ini bahan baku masih bercampur, antara kulit sapi dengan kulit kambing. Sehingga ketika pada saat akan dilakukan proses produksi pegawai harus memilah terlebih dahulu kulit yang akan diolah. Hal ini mengakibatkan proses jadi terlambat. Pengelompokan bahan kimia berdasarkan tipe proses penyamakan yang akan dilaksanakan.

2. Seiton

Metode ini merupakan kelanjutan dari seiri, dimana pemilahan kulit sapi dan kulit kambing yang datang dari supplier diletakkan pada rak yang berbeda. Selain lebih teratur juga akan berpengaruh pada kualitas material yang akan di olah. Selain penataan material kulit yang datang dari supplier dilakukan juga penataan pada kulit hasil penyamakan dan penyimpanan bahan kimia. Kemudian alat atau tools yang digunakan untuk proses penimbangan bahan kimia dan produksi dikelompokkan sesuai fungsinya dan diletakkan pada kotak khusus.

3. Seiso (Pembersihan)

Bersih-bersih sebenarnya bukan sebagai aktivitas khusus dari suatu pekerjaan, tapi pekerjaan ini merupakan kesatuan yang menjadi keseharian dari jadwal kerja seseorang. Dengan menggunakan Seiso ini maka area kerja bisa tetap bersih setelah mengerjakan pekerjaan maupun saat memulai 
pekerjaan tersebut. Dalam konsep ini maka akan menghindarkan dari kesalahan ataupun hal yang aneh saat bekerja.

Langkah yang sering dilakukan oleh seorang pekerja dalam konsep ini adalah dengan menata tools, setelah digunakan dikembalikan ke tempatnya dan dibersihkan dari kotoran. Jika tools bermasalah maka bisa diketahui dan digantikan dengan yang baru. Bila di kantor maka setelah bekerja, filefile ditata kembali pada tempatnya semula.

Kebersihan ini sangat penting, di kantor karyawan bisa menata kembali meja kerjanya dan sekelilingnya dari dokumen-dokumen yang tidak terpakai. Sampah-sampah dibuang pada tempat sampah. Kegiatan ini adalah satu kesatuan yang harus dilakukan setiap hari dalam jadwal kerja. Sebagai nilai tambah, ketika anda mencari ingin mengambil dokumen yang dibutuhkan maka tidak membutuhkan waktu lama dan segera bisa mendapatkannya dengan mudah. Kadang kebersihan ini dianggap sangat sepele namun hasilnya sangat luar biasa bagi karyawan. Kebersihan ini akan membantu proses bekerja dan juga proses operasional perusahaan. Kebersihan tidak hanya dilakukan di kantor tapi juga bisa dilakukan di tempat produksi atau pabrik.

4. Seiketsu.

Pada tahap ini lebih mengarah pada proses pemantapan terhadap metode 5S yang diterapkan. Pada tahap ini dilakukan suatu upaya bagaimana penerapan yang telah dilakukan tetap berlangsung terus menerus. Beberapa tanda dipasang sebagai alat pengingat bagi karyawan bagian produksi maupun non produksi. Seperti menjaga kebersihan dan kerapihan, mengembalikan alat pada rak ataupun pada kotak yang telah disediakan.

5. Shitsuke

Tahap ini merupakan bagian terakhir dari metode 5S.pada bagian ini lebih fokus bagaimana cara untuk membiasakan diri terhadap penerapan metode ini. Sehingga diperlukan kesadaran dari para pekerja untuk memiliki pola kerja yang sesuai dengan metode $5 \mathrm{~S}$ demi kenyamanan dan keamanan dalam bekerja.

\section{SIMPULAN}

Berdasarkan hasil pengumpulan dan pengolahan data didapatkan hasil bahwa layout lantai produksi belum optimal. Hal ini ditunjukkan dengantingginya ongkos material handling sebesar Rp. 346.190,5. Dengan menggunakan algoritma CRAFT dilakukan pertukaran departemen A dan B, B dengan C sehingga terjadi penurunan biaya material handling sebesar Rp. 18.924,4, sehingga ongkos material handling menjadi Rp. 327.266,1. Supaya jarak tempuh material berkurang maka area lantai produksi perlu diatur sedemikian rupa agar lebih pendek, sehingga bisa meminimumkan jarak perpindahan material dan gerkana mundur. Agar lantai produksi lebh rapi maka perlu penambahan rak untuk menyimpan alat produksi, material kulit yang akan diolah dan produk jadi dan mengoptimalkan penggunaan peralatan untuk mendapatkan satuan muatan yang tinggi.

\section{DAFTAR PUSTAKA}

Apple, James M. (1990). Tata Letak Pabrik dan Pemindahan Bahan. Edisi Ketiga, Institute Teknologi Bandung; Bandung.

Chang, Yih-Long. (2003). "WinQSB Decision Support Software for MS/OM”. John Wiley \& Sons, Inc

Dharmayanti, Indrani et all, (2016), Aplikasi Metode SLP Dalam Penataan Klaster Industri Kelapa Sawit (Studi Kasus Kawasan Industri Sei Mangkei), Jurnal Riset Industri , Vol. 10(1).

Heragu, S. (1997). Fasilities Design, PWS Publishing, Boston.

Hadiguna, Rika Ampuh dan Setiawan, Heri, 2008, “Tata Letak Pabrik”, Andi Yogyakarta, Yogyakarta.

Ningtyas, Agnes Novita. (2015), Perancangan Ulang tata Letak Fasilitas Produksi dengan Metode Grafik dan Craft untuk Minimasi OMH.

Prasetya, Yetta Yosi. (2015), Analisis Tata Letak Fasilitas dalam meminimasi Material Handling Cost (Studi Kasus Perush. Roti Matahari), Jurnal Gema Aktualita Vol. 4(1).

Pangestika, Jeni Widya. (2016), Usulan Relayout Tata Letak Fasilitas Produksi Menggunakan Metode SLP di Dept. Produksi Bag. OT Cair pada PT. IKP, Jurnal Inegrasi Sistem Industri, Vol. 3(I)

Sriyanto.(2016). Perancangan Ulang Tata Letak Fasilitas pada MPC PT. Pos Indonesia Cabang Semarang menggunakan metode SLP dan Class Based Storage. 